\title{
The Digital Bridge Between Turkey and Germany: Transnational Use of Digital Media in the Turkish Diaspora
}

\section{Çiğdem Bozdağ}

\section{Introduction}

Transnational migration not only changes the people who are on the move, but also the countries they leave behind through their ongoing transnational networks. Today, these networks are sustained to a great extent through digital media technologies. The experience of migration (before, during and after migrating) has changed throughout history due to constantly changing information and communication technologies (ICTs), among other factors (Clifford 1994; Kaya 2007). Changes in media technologies not only impact the availability of mass media, but also bring about new forms of interpersonal communication, especially through digital communication technologies. These transformations also influence relations of diasporic communities with their homelands. ${ }^{1}$ Homeland is today less of a mythical and emotional place left behind, but rather a constant and important part of lives of many migrants through the (digital) media, which serve, in a sense, as a digital bridge (Clifford 1994).

Not long ago, letters were the »small media « (Dayan 1999) of diaspora, and were one of the main communication channels to communicate with people back >home . More recently migrants, and the following generations, have enjoyed a greater range of available media which can be used to maintain social and economic networks, family relationships, and political affiliations, which transcend nation states (Hepp, Bozdağ and Suna 2012, Madianou and Miller 2012). This pa-

1 This research discusses the history, benefits and disadvantages of the term Diaspora critically and in more detail. However, such a discussion will be left out from this paper for more focused argumentation. Diaspora can be briefly defined here as an ethnic, transnational imagined community, which is constructed through the experience of dispersion from a real or imagined origin, and is marked by processes of transnational networking and cultural hybridization (for a discussion of the term cf. Clifford 1994, Cohen 1997, Brubaker 2005). 
per engages with the question of how different media technologies, especially digital media, are being used by the members of the Turkish diaspora - the largest diasporic community in Germany - in order to build and maintain networks with Turkey, their country of origin. Moreover, it discusses how media influence transnational relations between people in different places.

I will argue that ICTs intensify the transnational communication networks of migrants with their countries of origin to such an extent that they become a usual part of their everyday lives. Hence, digital media extend the communication space for what Asu Aksoy and Kevin Robins (2003) refer to as »banal transnationalism «. The >de-mystification « of life in the country of origin in the eyes of Turkish migrants is taken a step further with the digital communication technologies. Also, interpersonal communication becomes much cheaper, easier and possible in various ways (e-mail, SMS, VoIP etc.), but also probably less special and less mythical. The feelings of loss and longing are reduced through ongoing mediated communication, according to the interviewees. These possibilities of networking make it possible for small-scale businesses to operate as transnational entities. However, the technological capability of building intense transnational networks through ICTs does not necessarily increase people's interest in building such networks. How people use digital media to build networks in their countries of origin is much more related to their cultural identification patterns, as well as their socio-cultural contexts. Furthermore, because migrants are no longer as familiar with the cultural, social and political context of Turkey (or some of them distance themselves from it), banal transnationalism is marked by disruptions and feelings of estrangement.

\section{The Transnational Turn in Migration Studies}

Scholarship on migration was primarily concerned with issues related to the preservation of the nation for a long time, such as the social, cultural, economic and political integration of migrants in the national context. This focus on the nation state and its sustainment, and the fact that it was taken for granted in the social sciences, which Andreas Wimmer and Nina Glick-Schiller (2002) refer to as "methodological nationalism «, was increasingly questioned in the last quarter of the twentieth century. Transnationalism emerged as an alternative approach to the national paradigm in the field of migration studies and also influenced many researches in the field of media and migration, as well as this research (cf. Wimmer/ Glick-Schiller 2002; Faist 2007).

The transnational approach conceptualizes migrant communities whose lives are marked by various national and cultural contexts, beyond the national frame- 
works. Transnationalism is "grounded in the daily lives, activities, and social relationships of migrants " who are involved in ongoing transnational networks. On the one hand, migrants are consuming cultural products from their countries of origin, which they interpret in a new cultural context in the country of settlement. On the other hand, they are involved in interpersonal networks with family members and friends, whom they left behind. These networks are built through media communication, but also through remittances that they send, their visits, and their political activities that are related to the country of origin. The constant juxtaposition with different cultural contexts forces migrants to " confront, reinterpret and rework on complex identity constructs «(Glick-Schiller et al. 1992: 5). Migrant identities emerge in »transnational social spaces « through cultural tensions between national contexts that they experience, in addition to the processes of continuous negotiation and cultural hybridization (Clifford 1994: 315, Kaya 2007: 483). For many migrants, the country of origin is not necessarily a » final destination of return « or a "homeland « that immediately wakes feelings of familiarity or belonging (Kentel and Kaya 2005: 32). Furthermore, they are integrated in the political, cultural and economic spheres of both countries. Media technologies enable communication beyond territorial borders and offer migrants different possibilities for being involved in both contexts. In particular, the media's role in the strengthening of transnational networks has received a lot of attention among scholars of migration, as well as in communication and media studies, as will be discussed in the next section.

\section{Media and Migration: The State of the Research}

The research field of media and migration emerges at the intersection of different disciplines and various subjects (for an overview cf. Karim 2003, Bailey et al. 2007). Despite the transnational evolution in migration studies discussed in the previous section, a great deal of research, especially in the German context, still deals with national issues such as media's role in the political, social or cultural integration of migrants in the national context of the host country. Yet, the transnational approach also has an influence on different projects which recognize the hybrid character of migrants' identities and their transnational networks. For example, one of the classical works in the field is the ethnographic research of Marie Gillespie (1995) on cultural change and the role of television in the Punjabi community in Southhall, England. Gillespie (1995) argues that the »TV talk « in different contexts of migrants' everyday lives (e.g. on the school yard, at the dinner table, during TV consumption etc.) are crucial moments for negotiations of migrant identities and cultural hybridization. Similarly, Asu Aksoy and Kevin 
Robins (2003) analyze transnational television consumption among migrants from Turkey and argue that television brings the "ordinary, banal reality of Turkish life to the migrants living in London " (Aksoy and Robins 2003: 95). However, the transnational engagement with Turkish television does not always work because migrants are not necessarily familiar with the context of Turkey, and »familiarity « is a key element of television consumption (Aksoy and Robins 2003: 102). Therefore, migrants can experience feelings of estrangement and distance when they are confronted with daily images in transnational television.

Digital media influence various aspects of everyday life, and this is even more the case for members of diasporic communities since communication beyond borders has a central importance for them. Accordingly, the role of digital media for transnational networks, and identity construction of members of diaspora, has become a central subject in the field of media and migration in recent years (e. g. D'Hanaens et al. 2007; Hepp, Bozdağ and Suna 2012; Madianou and Miller 2012). For example, Mirca Madianou and David Miller (2012) analyze how families that are separated through transnational migration sustain their family ties through different online communication forms like internet telephony and so on. Whereas there are different researches focusing on the Turkish diaspora around Europe and their use of mass media (e.g. Ogan 2001; Aksoy and Robins 2003), there is still room for exploration about the role of digital media in the construction of transnational communication space. Therefore, this research deals with the use of digital media among the members of the Turkish diaspora in Germany and its possible outcomes for sociocultural change in terms of increasing banal transnationalism.

Although new media technologies bring about possibilities for new forms of transnationalism, they are not to be seen as driving forces of sociocultural change, as more techno-deterministic approaches would assume. Their role is to be understood in relation to the daily appropriation practices of their users, through which these technologies are shaped and gain their meaning (Madianou and Miller 2012). Accordingly, this paper will draw upon previous research I was involved in and give examples from the media appropriation patterns in daily lives of migrants, who use the digital media transnationally.

\section{Historical Background of the Turkish Mediascape in Germany}

The Turkish diaspora numbers over 2,500,000, and is the largest migrant group in Germany. Although migration between Turkey and Germany has a longer history, most Turkish people living in Germany today are either workers who came 
through the labor recruitment agreement (»Anwerbeabkommen «) between Turkey and Germany in 1961, or are descended from that generation (Karakaşoğlu 2007: 1054). The majority of migrant workers who came to Germany in the 1960 s and 70 s were men aiming to save as much money as possible and return to Turkey eventually. Similarly, German authorities anticipated that foreign workers would also return to their country of origin - hence, the term > Gastarbeiter (guest workers) - a term that was used until the 199os. After the end of the recruitment agreement ("Anwerbestopp") in 1973, migration to Germany from Turkey has continued more in the form of family reunions, and after the 1980s, also as a result of political refugees (Karakaşoğlu 2007: 1055). Many migrants themselves, as well as the German authorities, realized that the settlement of Turkish workers in Germany was not a temporary situation, but becoming a permanent fixture. However, only in 2005 was this situation officially recognized, and thereafter Germany was declared to be a country of immigration.

The development of the German-Turkish mediascape correlates with historical developments related to Turkish migration in Germany. For example, German authorities introduced the radio program »Radio Köln $\aleph^{2}$, a program intended for Turkish migrants to keep them abreast of developments in Turkey. Turks themselves had a similar view of Turkish migrants in Europe in the 196os and 1970 . Specifically, Turkish workers in Germany were perceived as expatriates ('gurbetçiler`) in a foreign country, who were expected to remain loyal to their countries of origin in political, economic and cultural senses. Moreover, the Turkish media sector capitalized on a potential market in Europe. The Turkish newspapers, Hürriyet and Milliyet, started to be sold in many German cities where Turkish migrants resided. Especially in the 1980s, VCR (video cassette recording) technology changed the Turkish mediascape in Germany and made the consumption of Turkish films very popular and accessible. These videos constituted a small ethnic market in Germany centered around small "Export-Import shops, " as they were mostly called (Weber-Menges 2006: 129). In the 1990s, satellite technology not only changed the mediascape of German-Turks, but also of Turkey in general, and this has led to the privatization of media sector. ${ }^{3}$ Through satellite technology

2 A Turkish speaking radio show of the public broadcasting radio WDR (Westdeutscher Rundfunk). The show started in 1964 as a one-hour daily program and contained especially news about Turkey, and is today part of the daily program of the multicultural oriented Radio Funkhaus Europa (one hour every day). It is also available as a (24 hour) online radio. The show is today much about Germany, especially issues that are related to migration. For more information and the podcast of the show: http://www.funkhauseuropa.de/sendungen/ koeln_radyosu/ [15.07.2012].

3 Although privatization of the media sector in Turkey was not legally the case in the beginning of 1990s, television channels such as Star TV and TeleON started transmitting their 
and the diversification of available media in Turkey, Turkish migrants in Germany were able to consume various Turkish programs and retain cultural and political familiarities with Turkey. Many Turkish channels recognized the economic potential of Turkish audiences in Europe, and have today specialized channels catering to their tastes such as Eurostar or Euro D. These channels mostly broadcast similar content with what is found in Turkey, except for advertisements which are directly targeted to Turks in Europe. Within this period, we can also observe the development of a »transcultural « media scene, which can be seen as a product of an ongoing process of cultural hybridization among Turks living in Germany, who increasingly refer to themselves as »German-Turks « (Weber-Menges 2006: 130). This hybrid cultural production in the diasporic mediascape is especially conspicuous in the films of German-Turkish directors such as Fatih Akın, or in the development of the Radio Station Radyo Metropol FM. ${ }^{4}$ Also, German programs aimed at migrants changed in tandem with the transformations in the perception of Turks in German society. Hence, instead of issues related to country of origin, cultural diversity or social, cultural, and political integration in Germany became more prominent.

Digital communication technologies, especially the internet, not only brought about new forms of communication that were not possible before, but they also changed the existing forms of communication extensively (e.g. internet television, online newspapers and radios). The internet widened the accessibility of information and programming, but also diversified content with more cultural content from Turkey available within a couple of clicks. These developments in media technologies also led to a diversification of transnational engagement of migrants with their country of origin, as I will argue through different examples in the next sections. On the internet there is also more scope for the development of a transnational space that reflects the cultural complexity of migrant communities through cheaper and easier ways of media production, in comparison to mass media production. ${ }^{5}$ In these transnational spaces, German-Turks also negotiate their perceptions of their countries of origin and engage, for example, in the practice

programs in Turkey through satellite technologies. This eventually led to the passing of privatization law in 1993, and to a diversification of Turkish television sector.

4 Radyo Metropol FM is a Turkish-speaking radio station which was started in 1999 in Berlin and expanded its transmission area to Stuttgart, Koblenz, Mainz, Wiesbaden, Mannheim and Ludwigshafen. The station can also be received online: http://www.metropolfm.de/ [29. 09. 2012].

5 There are different types of websites (e.g. web portals, dating websites, news websites, religious websites) that are produced by and for migrants in Germany. These websites are referred to here as diasporic websites. Diasporic websites are typically bi or multilingual. 
of TV-Talk, as Gillespie (1995) calls it, or in the exchange of views about political happenings, religion or popular culture in Turkey from their perspective.

\section{Media and Transnational Networks of the Turkish Diaspora in Germany}

The following sections are based on the materials of two different research projects. The first is a qualitative research project, "Communicative connectivity of ethnic minorities «, which was carried out between 2010 and 2011 at the University of Bremen (lead by Prof. Dr. Andreas Hepp) and funded by DFG (German Research Association). The project deals with communicative networking practices and cultural identities of the Turkish, Moroccan and Russian diaspora in Germany. The empirical data consists of observation notes, qualitative interviews, network diagrams and media diaries (Hepp, Bozdağ and Suna 2012). This paper discusses 37 cases related to the Turkish diaspora. The interviewees were from Bremen and Berlin, and very diverse in terms of their personal histories, economic, educational and religious backgrounds, as well as their media use. Secondly, examples from my doctoral research (2009-2012) will be presented - a media ethnography about diasporic websites, which draws on observations, field notes, interviews and threads from discussion forums on the German-Turkish websites Vaybee! (107 threads) and Turkish-Talk (108 threads).

Despite the diversity of Turkish migrants living in Germany, different types of media are relevant for all those who live in Germany and who are engaged in transnational networks. Recent studies have shown that most of the Turkish migrants use radio stations, newspapers, television channels and websites from Turkey and Germany at the same time. How intensively they use the media of each country, and how they combine these, vary quite extensively according to the cultural identities of the users, among other factors. These results show that Turkish migrants do not live in $>$ media enclaves, $<$ as suggested by many nation-state oriented theories of media and migration. Besides the media of the country of origin, they also use the German media with different intensity (Simon and Neuwöhner 2011). Nevertheless, this paper focuses, rather, on the transnational use of media to connect with the country of origin in different ways in order to scrutinize the role of digital media in building daily, transnational networks.

It is not easy to differentiate different kinds of media since the internet can be used for receiving television channels, television for receiving radio stations, a mobile phone can be used as a computer, and so on. Considering this tendency towards the convergence of media technologies, it makes sense to take different kinds of media as a whole into account in order to understand what people do 
with the media for what purposes. Consequently, this paper also analyzes different kinds of transnational media and their use. However, the overarching focus remains the digital media and its role in changing transnational networks of migrants with their countries of origin media.

\section{Cultural Identities and Transnational Media Use}

Our research, »Communicative Connectivity of Ethnic Minorities, « has shown that migrant's use of media is very much related to their feelings of belonging and identity articulations - in other words, different subjective representations of self in various ways and situations with regard to different cultural contexts. Not surprisingly, people who still identify themselves strongly with their culture of origin, for example as »Turks «, » Turks in a foreign country « and so on, also tend to use various media in order to communicate with people in their countries of origin or consume cultural products from these countries (newspapers, TV shows, music, inter alia). For this group of migrants, which we refer to as origin-oriented, the internet also serves as a bridge to the country of origin in a variety of ways. Recent research, including our own, shows that origin-oriented migrants do not constitute the majority of Turkish migrants living in Germany (cf. Kaya and Kentel 2005; Hepp, Bozdağ and Suna 2012). A second group of migrants identify themselves with both cultural contexts (countries of settlement and origin), and therefore also use (digital) media for both contexts. These hybrid identifications also manifest themselves in the broad use of the "hyphenated « term "German-Turk " (»Deutschtürke «) (Kaya 2007), which we generalized under the term »ethno-oriented $\aleph^{6}$ in order to refer to all three groups we analyzed. Cultural resources from the country of origin and the transnational interpersonal networks with people there, contribute to such cultural hybridization processes. The third group, the world-oriented, has a more cosmopolitan orientation in terms of his/her identity orientation, but also in terms of their media use, which typically extends beyond the contexts of the countries of settlement and origin. The identity orientations of people who tend to be in these different groups are co-articulated in the reach of their communicative networks (Table 1).

The table above summarizes different orientations in the Turkish diaspora. It is evident that the extent of transnational networks, in which migrants in the Turkish diaspora are involved, differ in relation to their cultural identification patterns

6 The name of this second group of migrants » ethno-oriented « does not suggest that the other groups do not have an ethnic identity, but rather emphasizes that questions of ethnicity and being in-between two ethnic cultures is central for these group of migrants. 


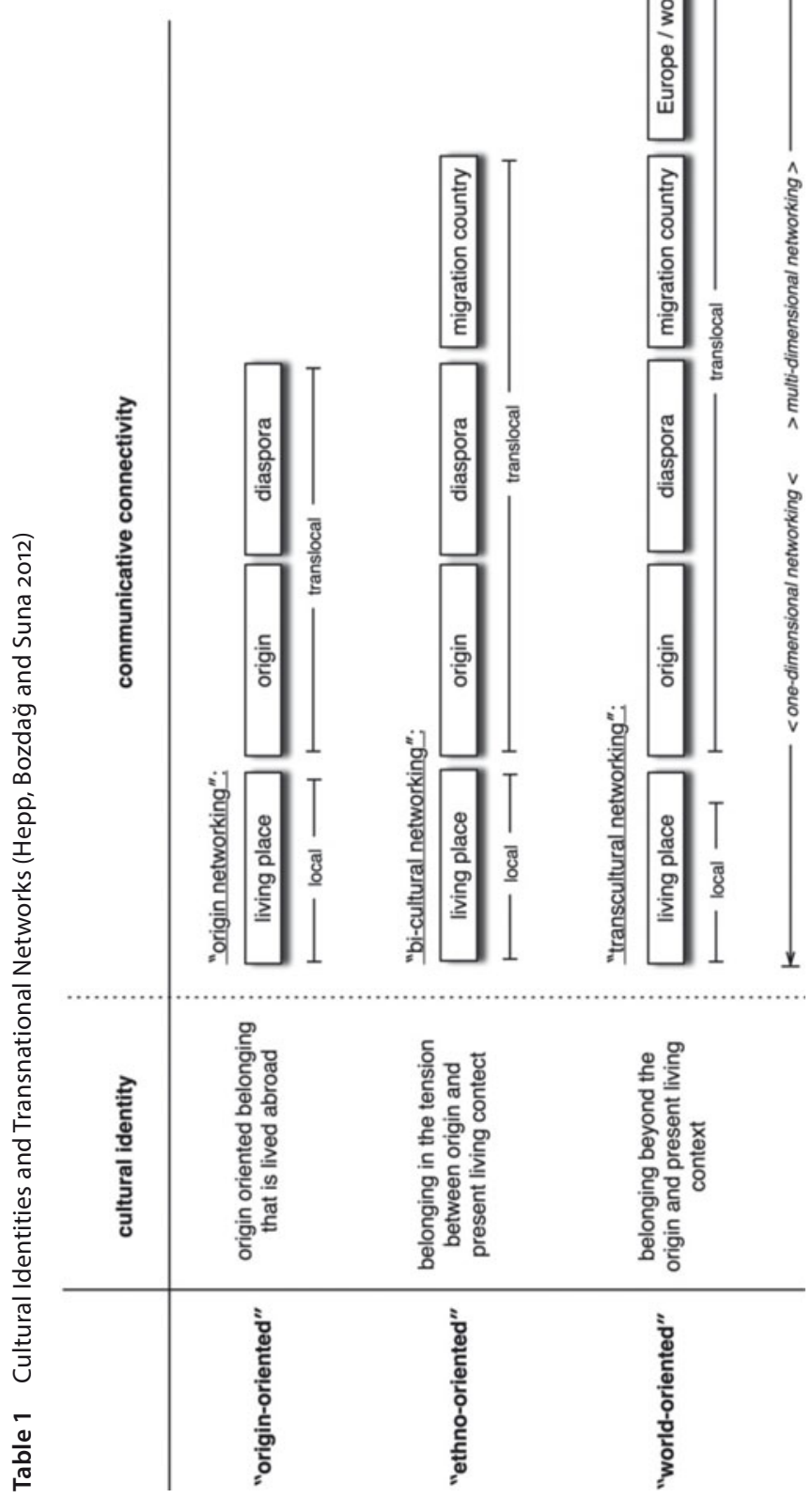


among other factors. Whereas all groups are somewhat involved in transnational networking practices with and without media, the diversity of the networks is different in all groups. The extent of people's networks and their identifications are also related to questions of migration history, educational and social background, gender and so on. For example, it is mostly the first generation migrants who strongly identify themselves with Turkey, whereas second and third generation migrants see themselves in-between two cultures, and their networks reflect this. The world-oriented migrants, who have more cosmopolitan orientations and have extensive networks around Europe and often beyond, are mostly a well-educated minority both within the analyzed migrant groups, and also in the Turkish diaspora generally. However, we cannot assume that people move progressively from origin-oriented towards the world-oriented category through the generations. There are world-oriented migrants in the first generation, and there are second and third generation migrants who see themselves as "Turkish nationalists «. These examples make it clear how complex the picture actually is. In light of this complexity, we need to avoid simplifying generalizations and linear modals of cultural change, and rather consider the inner diversity of these groups when analyzing patterns of banal transnationalism and media use in migrants' lives.

\section{Interpersonal Networks with the Country of Origin}

Digital media offer many different communication possibilities for migrants to their country of origin. Such transnational interpersonal networks did not just emerge with digital media, but were always a part of migrants' mediascapes in the form of "small media " such as letters, video recordings, and so on (Dayan 1999). Nonetheless, the possibilities of mediated interpersonal communication, beyond the borders of nation-states extended through the new technologies. When the interviewees spoke about communication with friends and family in Turkey, they mostly referred to the >old times, $<$ when many options for transnational communication did not exist, and they therefore appreciate today's communication technologies. For example, $\operatorname{Ferda}^{7}$ (f, 40) and her husband Hamit (m, 40), who both came to Germany as political refugees in the 1990s, state that they have new ways of talking to people in Turkey and this has mitigated their sense of longing for home. As Ferda puts it:

Before, there was longing and nostalgia and that is not there anymore, I think, I really ... Believe me, for example, our people here in abroad [gurbet], we called it abroad

7 The names of the interviewees have been changed in order to maintain their anonymity. 
[gurbet]. They had the need to go to Turkey every year. But people don't have this need to go to vacation any more. They might think, it is ok even if I do it only every second or third year. They can see their families every day. ${ }^{8}$

Hamit:

You say, turn the (web)camera on, ok, then you see them.

After the conversation above Ferda added that they used to call their relatives in Turkey through the landline mostly. Then, they started to chat with them when they bought a computer a few years ago, and afterwards they started to use internet telephony with webcam. The ease and affordability of transnational communication makes it possible for migrants to communicate with more people for longer durations. With the increase in frequency in communication, quotidian, as well as more serious matters, can be discussed more regularly. For example, Fatoş (f, 40) says she talks to her sister, her mother and her aunt almost every day. They exchange even the smallest details of their daily lives such as recipes, the Turkish serials they have been watching, and so on. Many interviewees mentioned similar experiences in communications with their friends and relatives in Turkey through the internet.

However, there are also restrictions to banal transnationalism through digital media. For example, not all interviewees were enthusiastic about talking with relatives for many hours. Yeliz ( $\mathrm{f}, 40$ ) explains that it is enough for her to ask how people in Turkey are doing, and say hello. She does not feel the need to » sit for hours « and ask again and again »how are you again? (»daha daha nasılsınız»). Others like Nilgün (f, 33) find it awkward to sit in front of a camera and talking.

Another restriction to transnational communication through digital media relates to media literacy - the skills needed to utilize different media technologies effectively. For example, the elderly interviewees, who were usually less familiar with technology, indicated mostly that they cannot use computers themselves. In order to communicate with their relatives, their others must assist them. Such media literacy shortcomings, and the inaccessibility of computers in general for some, likely exclude (especially older) migrants from participating directly in the transnational networks with Turkey. As explained, second and third generation children often play a mediating role in enabling greater participation for the elderly. For example, Orhan, who is 17 years old and a third generation German-Turk, sets up the computer and the chat server to link his family with relatives in Turkey. He is also the one who sends pictures to family members in Turkey with his

8 The interviews were in German or Turkish and were translated into English by the author. 
mobile phone. Other interviewees from younger generations shared similar stories about facilitating and helping maintain transnational links with their families in the country of origin.

For younger generations of Turkish migrants in Germany, Turkey is not necessarily a familiar place to them. It is, rather, a country that they became acquainted with through their visits, their parents' or grandparents' narratives, and mediated representations like texts, pictures and videos. The media also connect family members that might not otherwise have the opportunity to meet. Media also allow for the maintenance of old friendships or relations, in addition to providing a platform from which to meet new people. Gökçe (f, 33), for example, stayed in Turkey for a year, when she was in high school. The first thing she did when she registered in the social network site (SNS), Facebook, was to look for her old friends. Halim ( $m, 33)$, who is seldom in Turkey, is in contact with different people from Turkey through his SNS-group Employment Agency (»İs ve İş̧i bulma kurumu «). In other words, transnational social spaces, SNSs, and diasporic websites enable migrants not only to connect with other diaspora members, but also with people in their countries of origin, build new networks, sustain ongoing ones or revive old ones.

Media technologies also connect business associates. Today, even small-scale businesses have the possibility to operate on a transnational level. This is particularly useful for migrant business owners who still have social networks in their countries of origin. Travel agencies and export-import businesses in particular utilize these opportunities to sustain and expand their networks. An illustrative example is that of Nalan $(\mathrm{f}, 50)$, a partner in a dressmaking store in Turkey, which tailors the dresses that she then sells on in her shop in Germany. She explains how she manages to operate her transnational business with the help of different media:

I do this, God bless, there is e-mail today. I send the pictures [of the dresses] which I want to have. And the telephone is also flatrate, you can phone all day long. It is very cheap of course. There are also many ways to take pictures of what they have been sawing and to show it. From here, I can see and intervene and say don't do it like that, do it like this and all that. One doesn't need to fly there and back.

Nalan's wedding dress shop is very well equipped with different kinds of digital media, such as cameras, mobile phones with different lines, a webcam, and internet broadband connection. These media allow her to inexpensively remain connected with her business partners in Turkey daily. Her arrangement typifies the business model that many other migrants have adopted. However, technical equipment and skills are still prerequisite of mediated transnational networks. 
These different examples make it clear that media technologies make a daily exchange between Turkey and migrants in Germany possible in various ways. The quotidian character of transnational communication intensifies the connections beyond national borders, on the one hand. On the other hand, such interpersonal connections are often taken for granted, such that they become, in a sense, demythologized and »banalized «, like in the case of transnational television, as Aksoy and Robins (2003) argued.

\section{Diversification and Popular Cultural Products from Turkey}

The German-Turkish mediascape has become very diverse and complex through the internet and mobile communication technologies. Whereas many types of Turkish mass media became available online without spatial and temporal constraints, there are also new forms of media through which Turkish migrants can remain attuned to Turkish news and popular culture. Today, even the smallest local newspaper or radio station from Turkey can be reached within a couple of clicks. Although during the history of Turkish migration in Germany, different media were available from Turkey as discussed in the third section (e.g. TRT international, radio stations through satellite connection etc.), such diversity and intensity of transnational media consumption was not possible before the internet. This diversity of available, cultural and informational resources from Turkey, as well as the intensity of communication, allow a more reflexive and critical view about the country of origin, on the one hand (cf. for similar arguments on Satellite Television Aksoy and Robins 2003). On the other hand, it gives migrants a feeling of being closer to their country of origin, easing nostalgia. For example, Yeliz ( $f, 40)$ listens to radio stations from the northern region of Turkey around the Black Sea, where she comes from, to feel more connected to her hometown. Similar to Yeliz, Hakan $(\mathrm{m}, 26)$ also listens to radio stations from the hometown of his parents, Sultan Radio from Kahramanmaraş, and is enthusiastic about such a possibility:

I think it was Sultan Radio or something like that, no idea. I listened to that once, not bad at all. One has straight away the feeling that one is in Turkey, doesn't he? One listens to radio directly live from Turkey.

For younger users from the second generation of Turkish migrants, like Hakan, the internet offers a rich informational resource about Turkey, its history, politics and culture, and provides a sense of »being there, " as Hakan puts it - a feeling of being closer to their (parents') origin. Through the internet, migrants search for 
films, television series, music, newspapers, and magazines from Turkey. Different websites that gather these kinds of cultural resources like video-portals (diziizle. net, filmizle.net, gazeteoku.com, inter alia) are used by most of the interviewees with differing levels of frequency. Like in the case of interpersonal communication, younger generations of migrants use the internet more often for such purposes. The transnational use of the internet is, however, also not without restrictions. For example, the Turkish language skills of many younger migrants are not sufficient enough to read text-based resources on the internet. Aynur (f, 20) and Serap (f, 20), who are both third generation Turkish migrants in Germany, state that they find it quite difficult to understand Turkish newspapers, and therefore mostly hear about the news from Turkey through their parents. Diasporic websites such as Vaybee.de, Turkdunya.de or Turkish-Talk.com, which are both in Turkish and German, provide a transnational space on the internet through which these younger generations can learn about their country of origin. Through the interactive character of these websites, they can exchange their own views about Turkey from a diasporic perspective and all this in their own language, mostly a mixture of Turkish and German. Through these channels they remain updated about the happenings and the cultural scene in Turkey, as Orhan $(\mathrm{m}, 17)$ formulates it: »so one knows what is going on over there».

\section{Conclusion: What Kind of Bridge and for Whom?}

Media technologies build a bridge between migrants and their countries of origin, and this contributes to the emergence of transnational networks and cultures of diasporas. They also provide a mediated transnational space for the members of diasporas, as can be seen in the example of diasporic websites, in which discussions and negotiations about the country of origin take place. In this sense, media contributes to the emergence of banal transnationalism in many different ways, and also ensures that Turkish culture retains a greater presence in the lives of diasporic members. However, the intensity and meaning of these connections differ greatly depending on the social, educational, cultural backgrounds and identifications of the users of the media. There are disruptions in the transnational networks that are mediated through different media technologies due to differences in media literacy, interest in other cultural, political contexts, or social and cultural capital. Digital media technologies build a transnational bridge between Turkish migrants and Turkey, but not necessarily for everyone. Some are not able to utilize media to build transnational networks because of lack of financial resources, media literacy, language skills or cultural capital. In general, ICTs offer migrants new possibilities of action (Madianou and Miller 2012), in this case, for 
intensifying transnational networks and engaging in everyday practices with people and media from the country of origin. However, this banalization of transnational networks occurs at different intensity and pace among different migrants. Furthermore, migrants from Turkey, and indeed many migrants the world over, are people on the move in a complex, globalizing and shrinking world. Through mediated networks, Turkish migrants in Europe retain a connectedness with Turkey at a time when Turkey itself also becomes increasingly connected to other parts of the world through this bridge that is strengthened and expanded by digital media technologies.

\section{References}

Aksoy, Asu, Robins, Kevin. 2003. »Banal Transnationalism: The Difference that Television makes. «In The media of Diaspora, edited by Karim, Karim H.89-104. London: Routledge.

Bailey, Olga Guedes, Georgiou, Myria and Harindranath, Ramaswami (Eds.) Transnational lives and the media: re-imagining diaspora. Basingstoke: Palgrave Macmillan, 2007.

Brubaker, Rogers. 2005. "The >Diaspora ২ Diaspora. "Journal of Ethnic and Racial Studies 28,1: $1-19$.

Clifford, James. 1994. »Diasporas. « Cultural Anthropology 9,3: 302-38.

Cohen, Robin. Global Diasporas: An introduction. London: UCL Press, 1997.

Dayan, Daniel. 1999. "Media and Diasporas. "In Television and Common Knowledge, edited by Jostein Gripsrud, 18-33. London, New York: Routledge.

D’Hanaens, Leen; Koeman, Joyce, and Saeys, Frieda. 2007. » Digital Citizenship Among Ethnic Minority Youths in the Netherlands and Flanders. « New Media and Society 9,2: 278-99.

Faist, Thomas. 2007. »The transnational turn: migration and politics. « In Sociology of diaspora: a reader, edited by Ajaya Kumar Sahoo and Brij Maharaj, 227-66. Jaipur: Rawat Publications.

Gillespie, Marie. 1995. Television, Ethnicity and Cultural Change. London [et al.]: Routledge.

Hepp, Andreas, Bozdağ, Çiğdem, and Suna, Laura. 2012. »Mediatized Migrants: Media Cultures and Communicative Networking in the Diaspora."In Migration, Diaspora, and Information Technology in Global Societies, edited by Leopoldina Fortunati, Raul Pertierra and Jane Vincent, 172-88. New York \& London: Routledge.

Karakaşoğlu, Yasemin. 2007. »Türkische Arbeitswanderer in West-, Mittel- und Nordeuropa seit der Mitte der 1950er Jahre. In Enzyklopädie Migration in Europa: vom 17. Jahrhundert bis zur Gegenwart, « edited by Klaus J. Bade, 1054-61. Paderborn: Schöningh.

Karim, Karim H. (Ed.). The media of Diaspora. London \& New York: Routledge, 2003.

Kaya, Ayhan. 2007. "German-Turkish Transnational Space. A Separate Space of Their Own. «In The German Review 30,2: 483-502.

Kentel, Ferhat, Kaya, Ayhan. Euro-Turks. A Bridge or a breach between Turkey and European Union? A Comparative Study of German-Turks and French-Turks. Brussels: Center for European Policy Studies, 2005. 
Madianou, Mirca, Miller, Daniel. Migration and new media: transnational families and polymedia. London: Routledge, 2012.

Ogan, Christine L. Communication and identity in the Diaspora: Turkish migrants in Amsterdam and their use of media. Lanham: Lexington Books, 2001.

Simon, Erk, and Neuwöhner, Ulrich. 2011. »Medien und Migranten 2011, « Media Perspektiven 10: 458-70.

Wimmer, Andreas, and Glick-Schiller, Nina. 2002. »Methodological Nationalism and Beyond: Nation-State Building, Migration and the Social Sciences. « Global Networks 4,2: 301-34.

Weber-Menges, Sonia. 2006. »Die Entwicklung der Ethnomedien in Deutschland. «In Integration durch Massenmedien: Medien und Migration im internationalen Vergleich, edited by Rainer Geißler, 121-46. Bielefeld: Transcript-Verl.

Open Access. This chapter is distributed under the terms of the Creative Commons Attribution Noncommercial License, which permits any noncommercial use, distribution, and reproduction in any medium, provided the original author(s) and source are credited. 